\title{
Different dietary strategies for weight loss in obesity: role of energy and macronutrient content
}

\author{
I. Abete, M. D. Parra, M. A. Zulet and J. A. Martínez* \\ Department of Physiology and Nutrition, University of Navarra, Irunlarrea s/n, 31008 Pamplona, Spain
}

\begin{abstract}
Obesity is a chronic disorder caused by an imbalance of the energy metabolism with high associated burdens. Therefore, huge efforts are being currently devoted in studying new types of hypoenergetic diets and their composition, in order to characterise more specific, long-lasting and safe slimming protocols. A number of investigations are trying to determine the specific influence of the macronutrient distribution in energy-restricted diets on the management of excessive body weight. In this context, very-low-energy diets supplying between 1670 and $3350 \mathrm{~kJ}$ (400 and $800 \mathrm{kcal}) / \mathrm{d}$ have been beneficial in short-term treatments causing a weight loss of 300-500 g/d. Such strategies place more emphasis on energy restriction than on the macronutrient composition of the diet prescription. Weight loss produced by either low-carbohydrate or low-fat moderately energy-restricted diets ranges from 0.5 to $1.0 \mathrm{~kg} /$ week, while diets with high or moderately high protein content have also been applied in weight-reducing programmes by inducing losses of $0 \cdot 2-0.4 \mathrm{~kg} /$ week. Other factors that determine weight loss by dieting are sex, age, initial body weight, race, genetics, regional fat deposition, etc, which must be taken into account to explain the variability in the outcomes of different low-energy diets. Therefore, more research is needed about the impact of diets with different fuel substrates and foods on the characteristics of the weight-loss process.
\end{abstract}

Obesity: Macronutrient distribution: Energy-restricted diets: Low-carbohydrate diets: Low-fat diets: Weight loss

\section{Introduction}

Obesity is a major global health problem that has been associated with highly occurring disorders such as hypertension, type 2 diabetes, hyperinsulinaemia, dyslipidaemia, atherosclerosis and certain types of cancer (Cheah $\&$ Kam, 2005). Indeed, the epidemic of overweight and obesity, which is rising worldwide, inflicts not only a reduced life quality and large healthcare-associated costs, but also an increased risk of death (Wyatt, 2003; Popkin \& Gordon-Larsen, 2004).

Nowadays, the increasing Westernisation, urbanisation and mechanisation occurring in most countries around the world are accompanied by changes in the diet towards highenergy-yielding food consumption and a sedentary lifestyle (Popkin, 2001; Gordon-Larsen et al. 2004). This shift is also related to the current rapid changes in the rates of childhood and adult obesity (Swinburn et al. 2004). Trend analysis in relation to obesity suggests that in most countries the majority of the population is less active than they should be for maintaining good health, while they are simultaneously eating more than they need (Jebb, 2005). Weight gain is considered as a consequence of excessive energy intake as compared with energy expenditure, while successful weight loss depends upon achieving negative energy balance (Walker \& O'Dea, 2001). In this context, environmental influences, such as an inactive lifestyle and the consumption of energy-dense diets, appear of overriding importance on excessive weight gain in addition to genetic predisposition (Kemper et al. 2004; Marti et al. 2004).

Drugs currently available are able to help the obese patient lose up to $10 \mathrm{~kg}$ body weight within the first year of treatment, but their potential effectiveness in the long term, not least with regard to adverse effects, is unclear (Petersen \& Harper, 2004). Thus, pharmacological therapy is considered as a supplement to lifestyle intervention, which is a commonly used approach to treat the obese patient, through the adherence to specific dietary and/or physical exercise programmes. In fact, weight loss and, more importantly, long-term maintenance of the weight loss, is likely to involve behavioural changes in habits and dietary skills. Indeed, patients with better compliance to a slimming programme tend to achieve a better weight loss than those with poorer adherence (Petersen \& Harper, 2004).

Weight management in the obese may take into account the energy intake and the dietary macronutrient distribution. 
Therefore, a number of nutritional approaches and diets with different proportions of lipids, proteins and carbohydrates are being investigated (Table 1), which may be energy restricted or prescribed ad libitum (Bravata et al. 2003; Plodkowski \& St Jeor, 2003; Volek et al. 2005). However, not only the different macronutrient composition is of interest, but also the micronutrient content and specific dietary components could also be important (Rodriguez et al. 2005). Thus, previous studies have shown that dietary fibre improves the benefits of weight-reducing diets (Slavin, 2005), while PUFA and MUFA are factors contributing to weight loss and preventing weight gain (Grundy et al. 2002; Nettleton \& Katz, 2005). Furthermore, it has been proposed that the glycaemic index of foods can influence body-weight control (Acheson, 2004). Short-term studies suggest that low-glycaemic index carbohydrates and fibre intake could delay hunger and decrease subsequent energy intake compared with high-glycaemic index foods (Roberts, 2003). On the other hand, dietary Ca could play a role in controlling body weight, since epidemiological human studies support an association between long-term $\mathrm{Ca}$ intake, particularly from skimmed dairy products, and body-weight reduction (Schrager, 2005).

The present review reports a nutritional perspective about the implementation of different dietary strategies devised for overweight and obesity treatments based not only on energy restriction, but also on changes in the macronutrient distribution of the prescribed diet.

\section{Balanced low-energy diet}

The prescription of nutritionally equilibrated low-energy diets is a common strategy for body-weight reduction (Finer, 2001). These diets are designed according to traditional nutrient recommendations to supply a balanced ratio of protein (10-20\% energy), carbohydrate (50-65\% energy), and fat $(25-35 \%$ energy) in reduced quantities to provide an energy intake of $3350-6280 \mathrm{~kJ}$ $(800-1500 \mathrm{kcal}) / \mathrm{d}$ (Finer, 2001).

Hypoenergetic diets can achieve short-term weight loss, but often the slimming process is not sustainable in the long term (Pirozzo et al. 2002). The comparison of different nutritional strategies designed to produce weight loss suggests that specifically fat-restricted diets were no better than traditional energy-restricted diets in achieving longterm weight loss in overweight or obese individuals (Fig. 1).

A typical intervention study (Labayen et al. 2004) conducted in obese women (BMI $>30 \mathrm{~kg} / \mathrm{m}^{2}$ ), who followed a 10-week balanced dietary hypoenergetic intervention regimen, was able to induce a body-weight loss of 4.2 (SD 1.1$) \mathrm{kg}$, while the percentage body fat decreased by about $5 \%$. Another conventional trial evaluated during 2 months the efficacy and safety of a moderately hypoenergetic diet based on the Mediterranean diet model by assessing the changes in body composition and in the metabolic profile in obese women (De Lorenzo et al. 2001). Following such a diet, body weight decreased -4.9 (SD 0.9) kg and basal insulin decreased significantly too, indicating that balanced low-energy diets prevent loss of fat-free mass and improve metabolic parameters in obese individuals.

Conventional balanced low-energy diets seem to be most efficient when prescribed in addition to group therapy than other more restrictive diets (Arai et al. 1992), but the longterm success of dietary treatment for obesity based upon these approaches is unclear (Monnier et al. 2000).

A study about the effect of energy restriction and diet composition on weight loss and changes in plasma lipids and glucose levels concluded that all energy-restricted diets improve glycaemic control independently of diet composition, while only the lipoprotein profile was affected by the macronutrient composition (Heilbronn et al. 1999).

However, the traditional nutritionally adequate lowenergy diets frequently failed to promote stable weight losses, and the explanations for such limited success were mostly the 'poor adherence' to specific low-energy diets. Despite that, it has been reported that following a balanced but energy-restricted diet is accompanied by increases in fat utilisation (Labayen et al. 2004), weight loss induced by a balanced energy-restricted diet reduces BMR, which makes the maintenance of the slimming process difficult (Stubbs et al. 1996).

\section{Very-low-energy diets}

Very-low-energy diets (VLED) provide less than $3350 \mathrm{~kJ}$ $(800 \mathrm{kcal}) / \mathrm{d}$, being designed to cover the daily allowances of all essential nutritional requirements (Foster et al. 1992). The purpose of VLED is to achieve a large weight loss, while providing adequate nutrition and preserving vital lean body mass (Mustajoki \& Pekkarinen, 2001), averaging weight losses of $20 \mathrm{~kg}$ in 12 weeks in some cases (Wadden et al. 1983). The VLED are used in weight reduction programmes in many obesity clinical settings, but their usefulness in the treatment of obesity is not fully established. The applications of this kind of diets have no apparent serious harmful effects and can safely be used in patients suffering chronic diseases under supervision

Table 1. Summary of dietary features and associated weight losses achieved by different nutritional intervention strategies to treat obesity

\begin{tabular}{lllc}
\hline Diet & \multicolumn{1}{c}{ Features } & Application & Weight loss $(\mathrm{kg} /$ week) \\
\hline Hypoenergetic diets & $<5020 \mathrm{~kJ}(<1200 \mathrm{kcal}) / \mathrm{d}$ & $6-12$ months & $0.5-1.5$ \\
Very-low-energy diets & $<1670 \mathrm{~kJ}(<400 \mathrm{kcal}) / \mathrm{d}$ & $2-4$ weeks & $1.2-2 \cdot 0$ \\
High-fat diets $(\downarrow$ carbohydrate) & Ad libitum & $3-6$ months & $0.3-0.4$ \\
Low-fat diets $(\uparrow$ carbohydrate) & Energy restriction & $6-10$ weeks & $0.5-1.0$ \\
Low-fat diets $(\uparrow$ carbohydrate) & Ad libitum & $3-6$ months & $0.2-0.3$ \\
High-protein diets & Energy restriction & $4-12$ weeks & $0.5-1.0$ \\
\hline
\end{tabular}

$\downarrow$, Decreased; $\uparrow$, increased. 
(a)
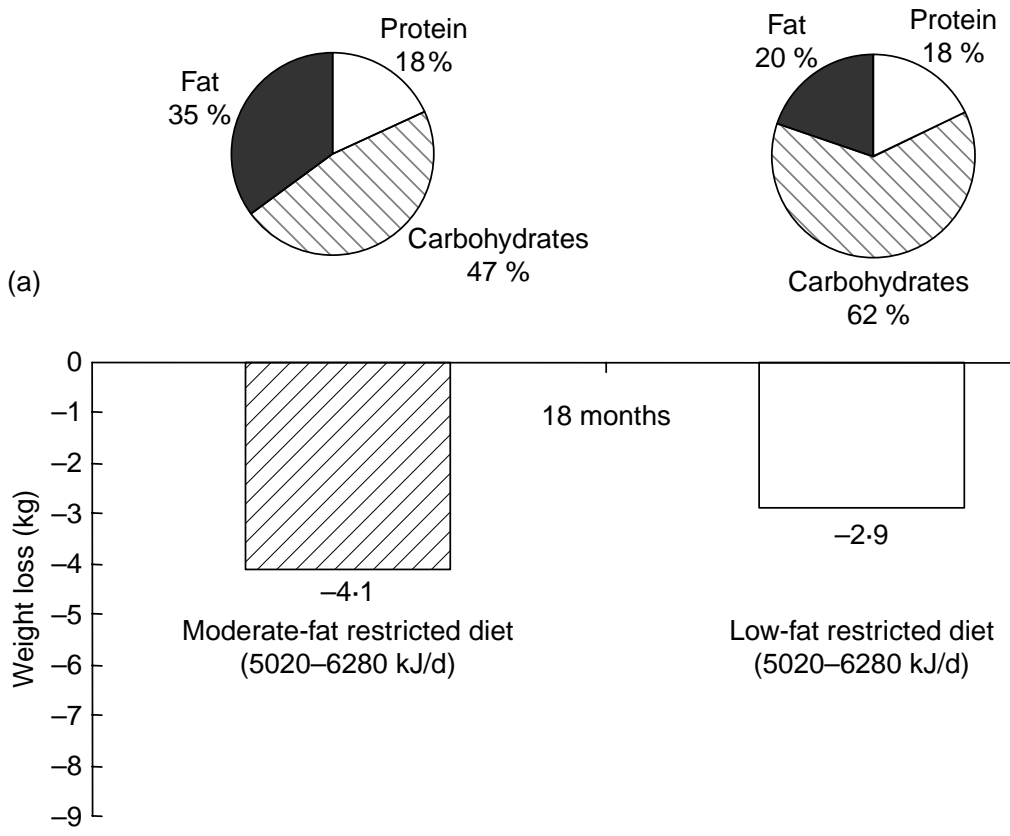

(b)
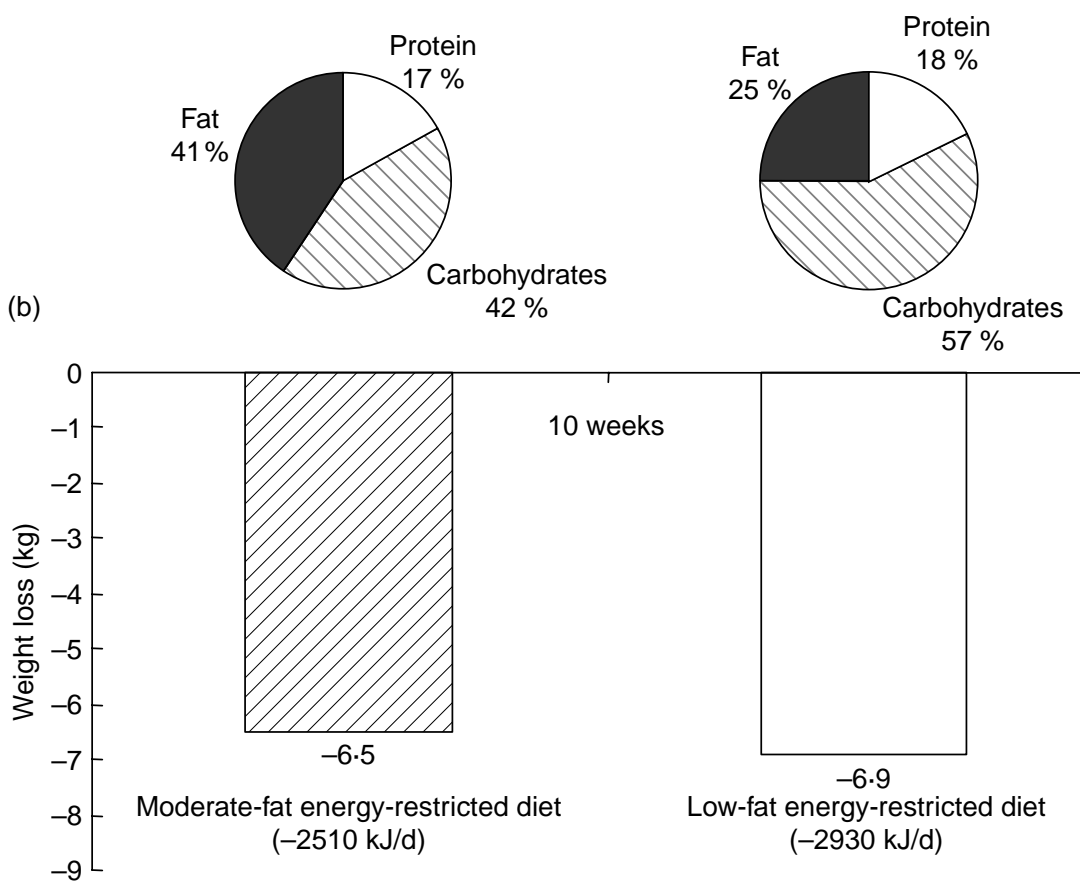

10 weeks

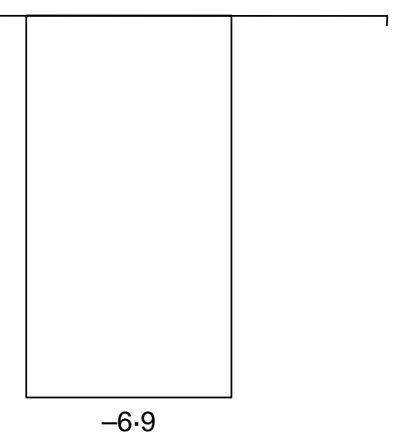

Low-fat energy-restricted diet $(-2930 \mathrm{~kJ} / \mathrm{d})$

Fig. 1. Weight losses induced by several hypoenergetic diets, following two energy-restricted approaches with different fat or carbohydrate content and similar energy coming from proteins. (a) From McManus et al. (2001); (b) from Petersen et al. (2006).

(Hart \& Warriner, 2005). Hence, VLED are used when rapid weight loss is needed because of an obesity-related disease or for bariatric surgery preparation (Mustajoki \& Pekkarinen, 2001).

A VLED can be based on normal food when a protein source, vitamins and trace elements are added (Wadden \& Stunkard, 1986). The amount of daily carbohydrate intake in VLED preparations varies from 10 to $80 \mathrm{~g}$, but the optimal amount of carbohydrate has not been established at present. An argument for low carbohydrate content is the fact that there is better protein sparing and fat mobilisation; however, this issue is still controversial despite early studies in this area (Wadden et al. 1983). Daily fibre intake varies from almost nothing to $20 \mathrm{~g}$ and the amount of fat supplied differs from 1 to $20 \mathrm{~g}$ (Kamrath et al. 1992).

The major problem to be resolved is the long-term maintenance of the large weight losses achieved with these diets (Wadden et al. 1983). In fact, VLED lead to greater initial weight loss, but the long-term outcome seems to be no better than more moderate energy-restricted diets 
(Hensrud, 2004). Metabolic rate and fat-free mass decrease secondary to rapid weight loss in patients after a VLED compared with moderate energy-restricted diets (Wadden et al. 1990). On the other hand, the combination of a VLED with a moderate energy-restricted diet, behaviour modification or medications does not improve long-term results produced by diet alone (Mustajoki \& Pekkarinen, 2001). However, it has been reported that ongoing, intermittent use of a VLED might improve long-term results (Lantz et al. 2003).

The application of behavioural therapies with and without VLED programmes revealed that the mean weight loss ranged from 9.2 to $19.3 \mathrm{~kg}$ and the non-VLED programmes ranged from $6 \cdot 2$ to $14.3 \mathrm{~kg}$ (Mustajoki \& Pekkarinen, 2001). Studies with 1- or 2-year follow-up have shown a mean weight loss of $7.2-12.9 \mathrm{~kg}$ with VLED and $5.7-9.5 \mathrm{~kg}$ without VLED (O’Neil \& Jarrell, 1992). Thus, no trial has conclusively shown that the long-term VLED are better than non-VLED programmes (Mustajoki \& Pekkarinen, 2001) because weight loss is rapidly regained (Wing, 1995; Hensrud, 2004).

Ryttig et al. (1997) compared the weight loss on a balanced low-energy diet to that of a VLED after 2 months of treatment and further compared the weight maintenance after 26 months in obese patients. During the first 2-month period, the mean body-weight loss in the VLED group was 18.9 (SD 7.1) kg compared with 7.2 (SD 4.8) kg in the hypoenergetic diet-treated group. Weight losses and dropout rates were similar in all groups. Previously, Kekwick \& Pawan (1956) looked for the factor with the greater effect on weight loss by VLED: restriction of energy or alteration in the proportions of macronutrient through different series of diets. In the first series, the proportions of protein, carbohydrate and fat were kept constant and the intake of energy was varied. In all of them protein supplied about $20 \%$, fat $33 \%$ and carbohydrate $47 \%$ of the energy. In diets of the second series, the patients followed dietary patterns in which the energy intake was kept constant at $4180 \mathrm{~kJ}$ $(1000 \mathrm{kcal}) / \mathrm{d}$ and $90 \%$ of it was provided, in turn, by carbohydrate, fat or protein. They found that weight loss was proportional to the deficiency in energy intake when the proportions of macronutrients were kept constant at each level of energy restriction, while when energy intake was constant at $4180 \mathrm{~kJ}(1000 \mathrm{kcal}) / \mathrm{d}$, the rate of weight loss varied greatly on diets of different composition (Kekwick \& Pawan, 1956).

The comparison of a $3350 \mathrm{~kJ}(800 \mathrm{kcal})$ mixed diet and a $3350 \mathrm{~kJ}$ ( $800 \mathrm{kcal}$ ) ketogenic low-carbohydrate high-fat diet on the composition of weight loss for 2 weeks revealed that subjects on the $3350 \mathrm{~kJ}$ ( $800 \mathrm{kcal})$ ketogenic diet lost $466 \cdot 6$ (SE $51.3) \mathrm{g} / \mathrm{d}$, while on the isoenergetic mixed diet, which provided carbohydrate and fat in conventional proportions, they lost 277.9 (SE 32.1) g/d (Yang \& Van Itallie, 1976). Interestingly, these researchers found that the mean quantity of fat lost during the ketogenic diet was $163.4 \mathrm{~g} / \mathrm{d}$, compared with $166.7 \mathrm{~g} / \mathrm{d}$ lost during the isoenergetic mixed diet, and the differences should be related to distinct water losses. On the other hand, Wadden et al. (1985) compared two VLED: protein-sparing modified fast $v$. protein-formula liquid diet. Both diets provided about $1670 \mathrm{~kJ}$ ( $400 \mathrm{kcal})$ daily. Analysis of the appetite data showed that protein-sparing-modified-fast subjects reported significantly less hunger and concerns with eating than liquid-diet subjects during 2 out of the 4 weeks on a VLED. Although the energy intake was similar, the form seemed to be crucial for the therapy success (Wadden et al. 1985).

At the moment, there is a general agreement that VLED should not be used alone, but always in connection with cognitive and behaviour counselling for permanent lifestyle changes (Mathus-Vliegen, 2005). During short periods of time, these diets are an alternative to other conservative weight-reduction programmes in patients who meet the indications, although research about the best formula for this type of diet is needed to improve the adherence.

\section{High-fat and low-carbohydrate diets}

High-fat diets are also being currently studied as an alternative in the nutritional treatment of obesity (Dansinger et al. 2005). These diets are commonly referred to as lowcarbohydrate diets, since they usually contain a relatively low proportion of carbohydrate (Jebb, 2005). The content of fat is usually about 45 to $65 \%$, while the carbohydrate content can be $<30 \%$ as energy per d (Fig. 2).

There is a widespread and growing interest in high-fat diets (for example, the 'Atkins diet') in relation to other more conventional approaches (McAuley et al. 2005). Individuals are attracted to follow low-carbohydrate diets because they are prone to think that energy intake is not important in a slimming programme and that they can eat as much fat as they like and still lose weight (Roberts, 2001; Ornish, 2004). The mechanisms responsible for decreased energy intake as induced by a low-carbohydrate diet with unrestricted protein and fat intake are not completely elucidated, but the higher consumption of protein may play a role in limiting food intake, through changes in plasma or central satiety factors or through other specific mediators that affect appetite and dietary adherence (Foster et al. 2003; Mithieux et al. 2005). This fact raises the possibility that a very-low-carbohydrate diet, normally associated with a high protein intake, could be more satiating. Many short-term studies suggest that individuals on low-carbohydrate diets voluntarily reduce their food intake (Volek et al. 2000). Energy intake restriction can also be related to the monotony or simplicity of the diet, because food carbohydrate choices are greatly limited by the requirements of minimising carbohydrates intake (Brehm et al. 2003; Samaha et al. 2003).

Freedman et al. (2001) stated that individuals consuming high-fat, low-carbohydrate diets may lose weight because the intake of protein and fat is self-limiting and overall energy intake is decreased. Many individuals following this diet successfully lose weight in the short term; however, few can sustain the significant dietary and lifestyle changes required to maintain losses over the long term (Wilkinson \& McCargar, 2004). Furthermore, restricting carbohydrates involves fat mobilisation producing ketone bodies. In this condition, the key benefit is that blood glucose and insulin levels are reduced, and appetite is suppressed. Several authors contend that a high-fat, low-carbohydrate diet results in weight loss, body fat loss, preservation of lean body mass, and correction of serious medical complications 
of diabetes (Bernstein, 1997), heart disease, and high blood pressure (Atkins, 1992). Indeed, the low-carbohydrate diet brings a dramatic weight reduction within the first few days, but much of this weight is a loss of glycogen and protein accompanied by a depletion of large quantities of water and minerals. Still, for many individuals the low-carbohydrate diet is apparently believed to be associated with a greater weight loss with less effort than conventional or highcarbohydrate diets in the longer term (Bravata et al. 2003); despite that, controlled trials have only recently been carried out concerning this issue following energy restriction or $\mathrm{ad}$ libitum approaches (Fig. 2).

In this context, Foster et al. (2003) conducted a trial to evaluate the efficacy of a high-fat low-carbohydrate diet on weight loss. Obese men and women were randomly assigned to either an ad libitum low-carbohydrate, highprotein, high-fat diet (without restricting consumption of fat and protein) or a low-energy, high-carbohydrate, low-fat diet designed to contain $5020-6280 \mathrm{~kJ}(1200-1500 \mathrm{kcal}) / \mathrm{d}$ for women and $6280-7530 \mathrm{~kJ}(1500-1800 \mathrm{kcal}) / \mathrm{d}$ for men (60\% carbohydrate, $25 \%$ fat, $15 \%$ protein). In the high-fat group, carbohydrate intake was limited to $20 \mathrm{~g} / \mathrm{d}$ for the first 2 weeks and then it was gradually increased until a stable and desired weight was achieved. Subjects on the lowcarbohydrate diet lost more weight than subjects on the conventional diet at 3 months ( -6.8 (SE 5.0) v. - 2.7 (SE $3.7) \%$ body weight) and 6 months (-7.0 (SE 6.5) v. -3.2 (SE 5.6$) \%$ body weight), although the differences at 12

(a)
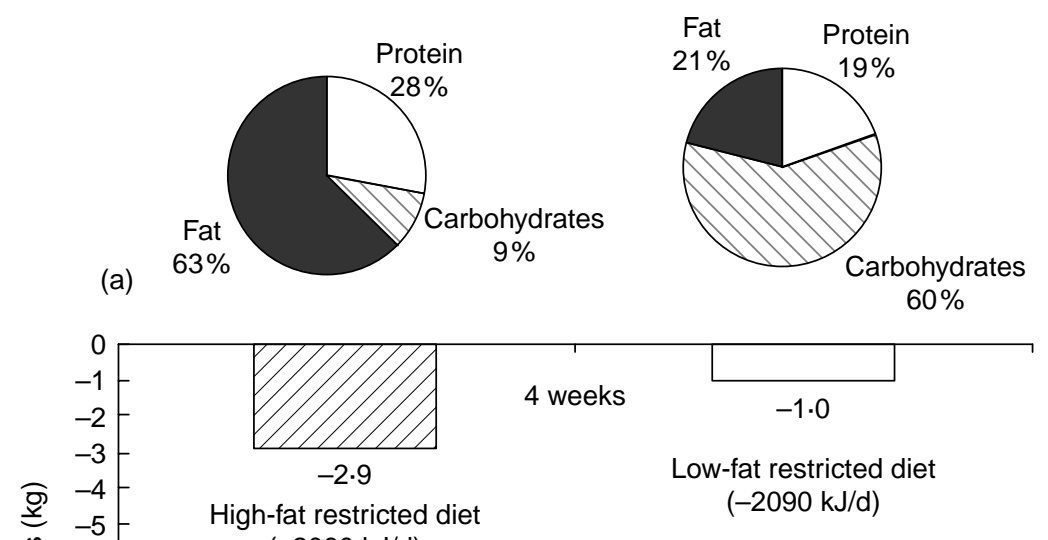

(b)
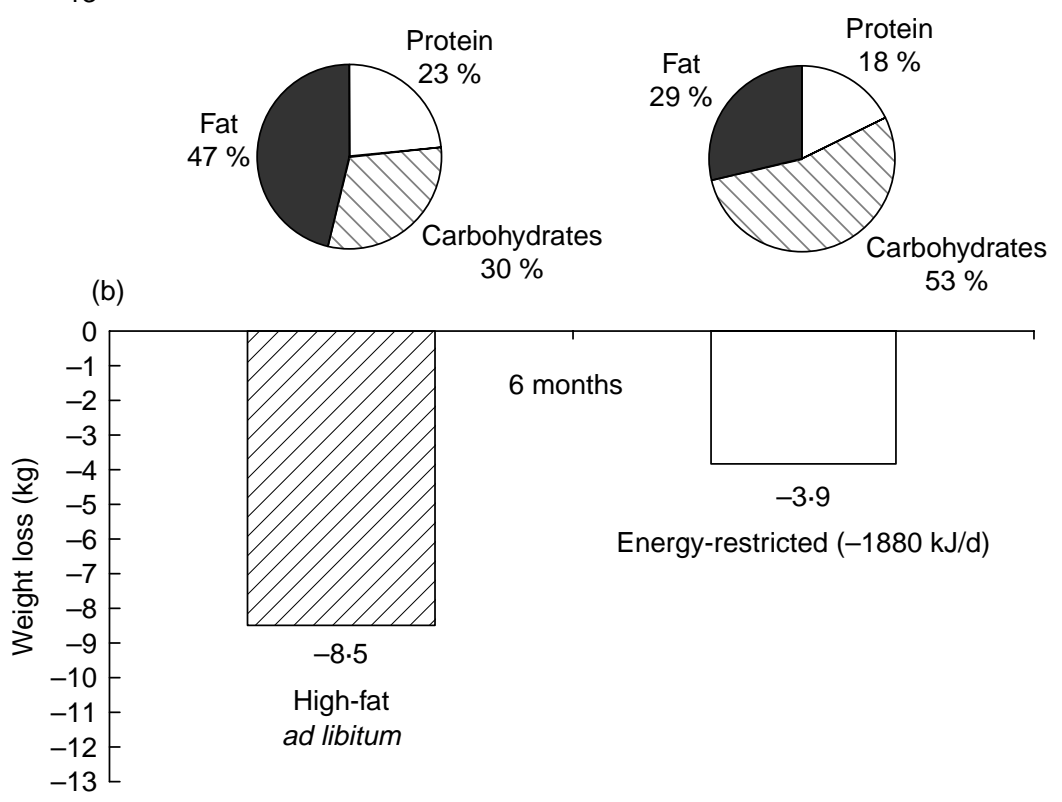

Fig. 2. Weight losses induced by diets with very different fat content (high $v$. low) when prescribed ad libitum or under an energy-restriction pattern. (a) From Volek et al. (2004); (b) from Brehm et al. (2003). 
months were not significant. The analysis of the differences in weight loss in this trial demonstrates an overall greater energy deficit in the low-carbohydrate group, which contrasted with the instructions to reduce energy intake in the conventional-diet group (Foster et al. 2003).

Additionally, Brehm et al. (2003) found a spontaneous restriction of food intake in a high-fat low-carbohydrate group to an equal level to that of the control subjects, who were following a prescribed restriction of energy. In this intervention trial, obese volunteers were randomised to follow during 6 months either an ad libitum very-lowcarbohydrate diet or an energy-restricted diet with $29 \%$ energy as fat. The very-low-carbohydrate group lost more weight $(-8.5$ (SE 1.0) v. $-3.9($ SE 1.0$) \mathrm{kg})$ and more body fat $(-4.8(\operatorname{SE~} 0.67) v .-2.0(\operatorname{SE~} 0.75) \mathrm{kg})$ than the low-fatdiet group after 6 months (Fig. 2).

Later, Stern et al. (2004) reported preliminary results at 6 months and final results at 1 year on obese individuals following a high-fat low-carbohydrate regimen. Participants received counselling to either restrict carbohydrate intake to less than $30 \mathrm{~g} / \mathrm{d}$ or to restrict energy intake by $2090 \mathrm{~kJ}$ $(500 \mathrm{kcal}) / \mathrm{d}$ with less than $30 \%$ energy from fat. Individuals on the low-carbohydrate diet maintained most of their 6month weight loss, whereas those on the conventional diet continued losing weight throughout the year. The final weight loss at 1 year was not different between both strategies.

Furthermore, Yancy et al. (2004) fed overweight, hyperlipidaemic volunteers either a low-carbohydrate diet (less than $20 \mathrm{~g}$ carbohydrate daily) or a low-fat diet (with less than $30 \%$ fat, $<300 \mathrm{mg}$ cholesterol daily and a deficit of $2090-4180 \mathrm{~kJ}(500-1000 \mathrm{kcal}) / \mathrm{d})$ to induce weight loss. After 24 weeks of treatment, weight loss was greater in the low-carbohydrate- than in the low-fat-diet group (mean change, -12.9 v. $-6.7 \%)$. Patients in both groups lost substantially more fat mass (change, $-9.4 \mathrm{~kg}$ with the lowcarbohydrate diet $v .-4.8 \mathrm{~g}$ with the low-fat diet) than fatfree mass (change, -3.3 v. $-2.4 \mathrm{~kg}$, respectively).

McAuley et al. (2005) compared in a randomised trial a high-fat, a high-protein and a conventional diet in overweight insulin-resistant women. Body weight, waist circumference, triacylglycerols and insulin levels decreased with all three diets, but, apart from insulin, the reductions were significantly greater in the high-fat and high-protein groups than in the conventional-diet group.

On the other hand, the type of fat in the diet may play an important role (Mozaffarian, 2005). Thus, higher proportions of PUFA have been associated with improvements in cardiovascular risk factors (Nettleton \& Katz, 2005).

No definitive evidence exists to suggest that high-fat lowcarbohydrate diets have a metabolic disadvantage over more conventional diets for weight reduction (Astrup et al. 2004). Studies consistently show that under conditions of negative energy balance, weight loss is more a function of energy intake, rather than diet composition. In some cases, individuals on high-fat low-carbohydrate diets appear to lose weight because they consume less energy.

\section{High-carbohydrate and low-fat diets}

Low-fat diets are specifically designed to promote weight loss through a reduction of fat consumption in order to decrease energy intake, which is usually accompanied by a high or moderately high carbohydrate supply (Strasser \& Pichler, 2004). These high-carbohydrate low-fat diets are based primarily on the intake of vegetables, fruits, whole grains and beans, non-fat dairy products and small amounts of white flour, sugar and animal protein, which may benefit from a rotating model for changing the variety of specific food groups (Raynor et al. 2004). The low-fat approach has been applied either in energy-restricted protocols, but also in ad libitum strategies (Astrup et al. 2002).

Diets with a high carbohydrate (low fat) content may provide protection against weight gain, but if the diet is rich in sugar, this association may not apply (Swinburn et al. 2004). Simple sugars have hedonistic value and sweetening increases the palatability of many foods, which may lead to overconsumption (Drewnowski, 1999). Research in this area is complicated by the diversity of dietary carbohydrates, which may be identified on the basis of their fibre content, proportion of whole grain, non-milk extrinsic sugar or added sugar content (Jebb, 2005).

There are important associations between the type of carbohydrate consumed and the risk of metabolic diseases (Jebb, 2005). Ad libitum programmes based upon low-fat product intake have shown that the nature of the carbohydrate content, (single v. complex) could be involved in the weight evolution (Astrup et al. 2002). Low-fat highcarbohydrate diets usually mean consuming more highcomplex carbohydrates and high-fibre foods due to the reduced energy value of these compounds as compared with lipids (Raben et al. 2002). This low energy density strategy enables individuals to eat as much as they want, and to lose weight safely without apparent hunger (Freedman et al. 2001), while low-fat energy-restricted diets combine a reduced fat intake within a hypoenergetic diet.

The prescription of hypoenergetic low-fat diets to reduce body weight with at least $55 \%$ of the energy coming from carbohydrates has shown that a reduced content from fat $(<25 \%)$ is associated with similar (Pelkman et al. 2004; Petersen et al. 2006) or lower weight losses (McManus et al. 2001; Volek et al. 2004), although a specific role from carbohydrate (quality and quantity) or protein intake should not be discarded in such experimental outcomes (Figs. 1, 2 and 3). Also, the fatty acid composition, i.e. long-chain triacylglycerols $v$. medium-chain triacylglycerols (Kasai et al. 2003; St-Onge \& Jones, 2003), or the MUFA v. PUFA content (Colette et al. 2003; Pelkman et al. 2004), of the slimming diets could be involved in the weight-loss evolution (Fig. 3).

Hays et al. (2004) designed a study to examine the effect of a 12-week ad libitum high-carbohydrate diet with different fibre content. A control diet $(1.7 \mathrm{~g}$ fibre $/ 1000 \mathrm{~kJ}$; $7 \mathrm{~g}$ fibre $/ 1000 \mathrm{kcal})$ and a high-carbohydrate diet $(6.2 \mathrm{~g}$ fibre $/ 1000 \mathrm{~kJ} ; 26 \mathrm{~g}$ fibre $/ 1000 \mathrm{kcal})$ were investigated (Fig. 4). The low-fat groups with fibre lost more body weight $(-3.2($ SEM 1.2$) \mathrm{kg}$ ) and a higher percentage of body fat $(-2.2 \%(\operatorname{SEM} 1.2) \%)$ than controls $(0.1$ (SEM 0.6) kg and $0.2 \%$ (SEM 0.6$) \%$ ) respectively, even with no measurable decrease in total energy intake.

Also, Poppitt et al. (2002) studied the long-term effects of an ad libitum high-carbohydrate low-fat diet. Thus, subjects with metabolic risk factors received a control diet, 


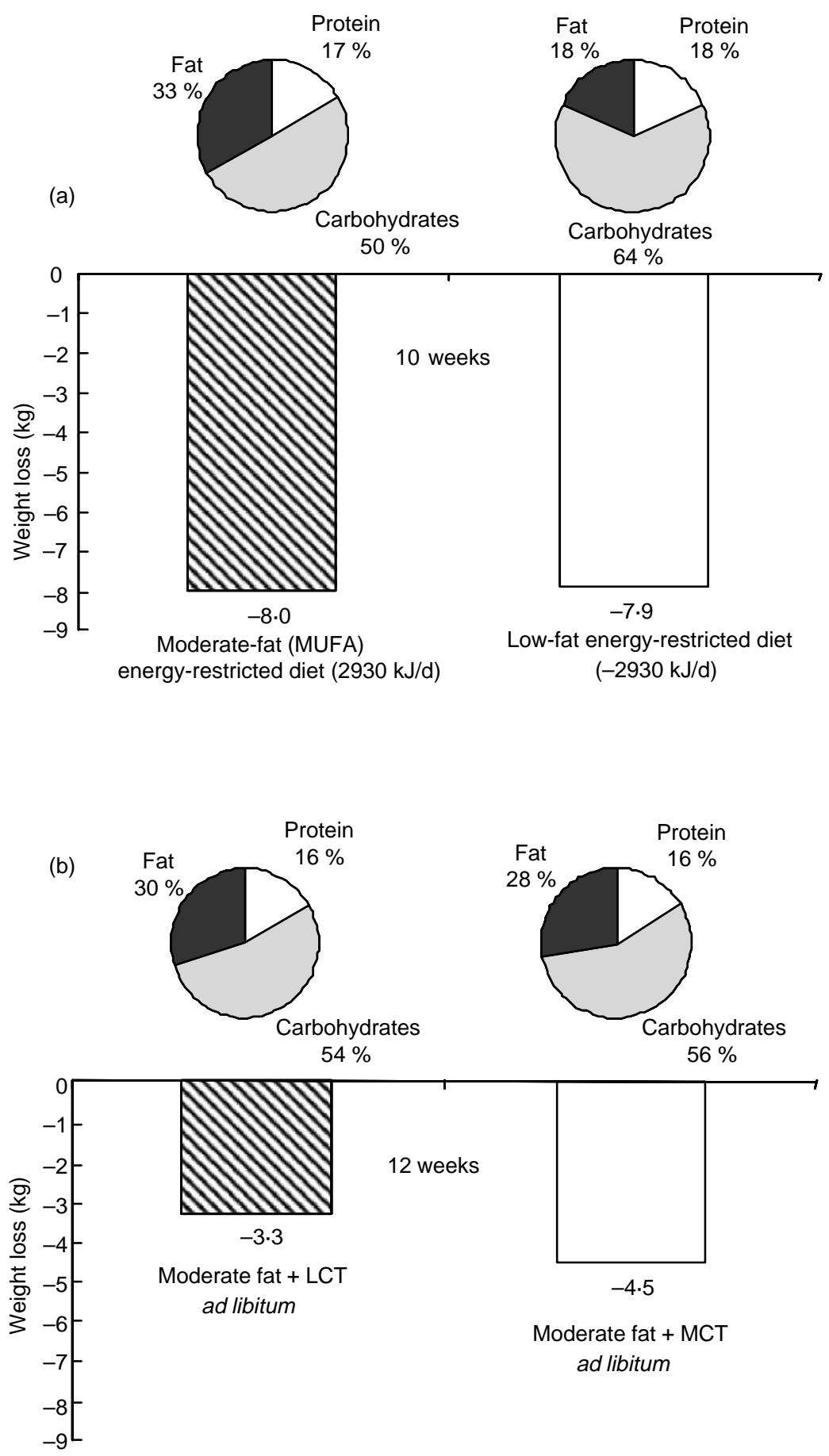

Fig. 3. Weight losses induced by low- to moderate-fat-containing diets with different MUFA or long-chain triacylglycerol (LCT) or medium-chain triacylglycerol (MCT) content, and prescribed following energy-restricted or ad libitum approaches. (a) From Pelkman et al. (2004); (b) from Kasai et al. (2003).

a high-complex-carbohydrate low-fat diet or a high-simplecarbohydrate low-fat diet for 6 months. Between 0 and 6 months, body weight changed by $1.03,-4.25$ and $-0.28 \mathrm{~kg}$ in the control, complex-carbohydrate low-fat, and simplecarbohydrate low-fat groups, respectively. Only in the complex-carbohydrate low-fat group did the BMI decrease significantly (Poppitt et al. 2002). These findings are complemented by data from a study of Saris et al. (2000), in which moderately obese adults were allocated for 6 months either to a seasonal or a control group (no intervention) or to two experimental ad libitum groups with different carbohydrate nature (simple v. complex). Body-weight loss in the high-simple-carbohydrate low-fat and highcomplex-carbohydrate low-fat groups was 0.9 and $1.8 \mathrm{~kg}$, 

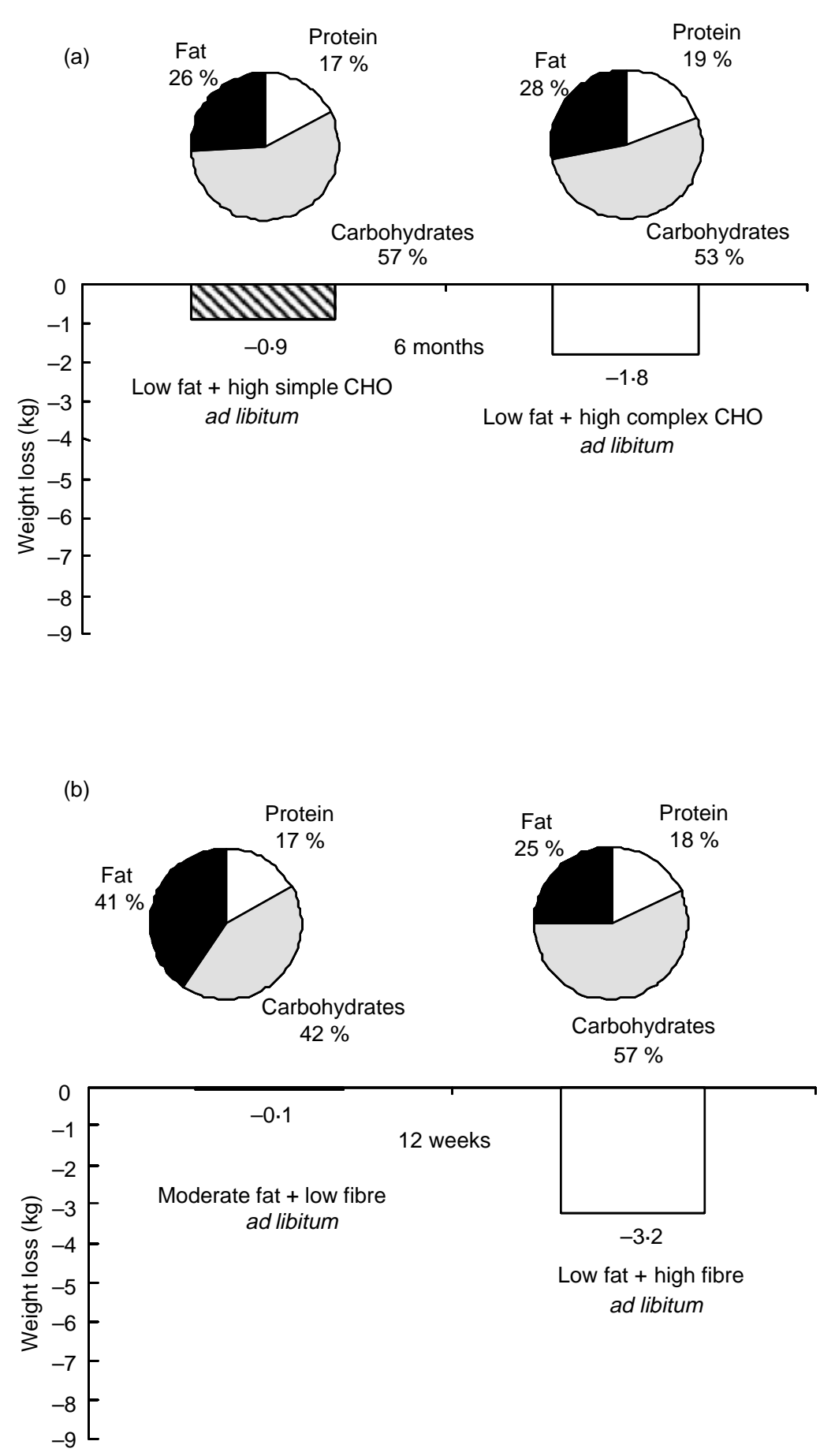

Fig. 4. Weight losses induced by ad libitum diets with different type of carbohydrate or fibre content and low-to-moderate fat amounts. (a) From Saris et al. (2000); (b) from Hays et al. (2004).

while the control and seasonal groups eventually gained weight $(0.8$ and $0.1 \mathrm{~kg})$ along the trial (Fig. 4).

Another study from Mueller-Cunningham et al. (2003) demonstrated that adherence to a high-carbohydrate verylow-fat diet (less than $15 \%$ energy intake) that was consumed during an 8-month period ad libitum caused weight loss in the 5-10\% range, while the decrease in percentage body fat was of 2.7 (SD 0.2) \%. Because of a possible reduction in vitamin $\mathrm{E}$ and $n-3$ fatty acid intake, emphasis on foods with high content in these nutrients may need to be encouraged for those consuming a highcarbohydrate very-low-fat diet. So, the effects of the inclusion of long-chain triacylglycerols and medium-chain triacylglycerols in diets with a relatively high content of carbohydrate $(>50 \%)$ and low lipid content have been explored in two independent intervention trials (Kasai et al. 2003; St-Onge \& Jones, 2003), which have revealed that medium-chain triacylglycerols intake may produce a greater 
fat oxidation leading to a higher weight loss despite ad libitum feeding (Fig. 3). Comparing the effect of low- and high-fat diets on nutrient intakes, it was concluded that lowfat diets may not provide sufficient energy, essential fatty acids and micronutrients (especially vitamin $\mathrm{E}$ and $\mathrm{Zn}$ ) for healthy untrained individuals. Interestingly, increasing fat intake to $50 \%$ of energy improved nutritional status, and did not negatively affect some cardiovascular risk factors (Meksawan et al. 2004).

Ad libitum, fat-reduced diets seem to be effective in preventing weight regain after weight loss (Toubro \& Astrup, 1997) and can induce a weight loss of about $5-10 \mathrm{~kg}$ (Astrup et al. 1997). Anderson et al. (2000) suggested that diets low in saturated fat and high in carbohydrate and dietary fibre significantly improve health by increasing insulin sensitivity and lowering the risk of CVD.

The current evidence suggests that low-fat standardcarbohydrate diets are safe, efficacious for weight loss, and improve cardiovascular risk profiles, but it is important that these type of diets should be based on complex carbohydrates and fibre (Fig. 4), not sugar, and that moderate fat intakes should include mainly monounsaturated and polyunsaturated fats (avoiding trans or saturated fats). Moreover, the role of low-fat hypoenergetic diets may be different than when applied in ad libitum conditions for preventing weight gain (Astrup et al. 2002).

\section{High-protein low-carbohydrate diets}

High-protein low-carbohydrate diets are gaining popularity, although there is still insufficient evidence to make recommendations for or against the use of these diets. These dietary approaches have been proposed as an alternative to conventional diets, in order to reduce or treat the risk of obesity, CVD and type 2 diabetes mellitus (Noakes et al. 2005). These nutritional plans commonly advocate dramatic reductions in carbohydrate intake coupled with high fat consumption producing a ketotic acidosis, which could be involved in the appetitesuppressing effect (Bravata et al. 2003).

High-protein low-carbohydrate diets are effective for weight loss (Fig. 5) as demonstrated by Skov et al. (1999), who found a higher reduction in body weight $(8.9 v .5 \cdot 1 \mathrm{~kg})$ when offered on an ad libitum pattern during 6 months between a high-protein diet ( $25 \%$ energy) as compared with a normal-protein diet (12\% energy). Also, another study designed by Samaha et al. (2003) was carried out with subjects assigned to a high-fat low-carbohydrate diet providing a moderately high protein content ( $22 \%$ energy) as compared with a traditional supply of protein $(16 \%)$. The subjects assigned to the normal-protein diet were advised to reduce energy intake sufficient to create a deficit of $2090 \mathrm{~kJ}$ $(500 \mathrm{kcal})$ per d, with $35 \%$ or less of total energy derived from fat. Compared with the subjects on the control-protein diet, subjects on the moderately high-protein diet reported a non-significantly greater reduction in energy intake. This intervention trial revealed that subjects on the diet containing more protein lost more weight during the 6-month study than those on the control-protein diet did $(-5.8(\mathrm{SD} 8.6)$ v. $-1.9(\mathrm{SD} 4.2) \mathrm{kg})$, which may be also explained by differences in the fat and carbohydrate content between both diets (Fig. 5).

An increase in dietary protein from $15 \%$ to $30 \%$ energy with a constant carbohydrate intake results in significant weight loss (Parker et al. 2002; Weigle et al. 2005). However, a systematic review reported that the weight loss is associated with the duration of the diet and the restriction of energy intake with no association to carbohydrate restriction itself (Freedman et al. 2001; Luscombe et al. 2003). In this context, Due et al. (2004) compared 6 months of ad libitum high protein intake ( $25 \%$ energy) with a diet of medium protein content $(12 \%$ energy), reporting that a fatreduced high-protein diet had more favourable effects on body-weight loss, providing a better long-term maintenance of reduced intra-abdominal fat stores (Due et al. 2004). Furthermore, Johnston et al. (2004) compared two 6-week low-fat energy-restricted diets: high-protein (30\% energy) or high-carbohydrate (60\% energy). They found that both diets were equally effective at reducing body weight and fat mass. However, subjects consuming the high-protein diet reported more satisfaction and less hunger.

Another study conducted by Layman et al. (2003) examined the efficacy of two hypoenergetic diets with modified carbohydrate:protein ratios on the weight-loss process. After consuming the diets for 10 weeks, they demonstrated that increasing the proportion of protein to carbohydrate in the diet of adult women has positive effects on body composition and satiety during weight loss.

Despite it being known that high-protein low-carbohydrate diets produce an increased weight loss over 3-6 months, the long-term results are unclear (Astrup et al. 2004). The carbohydrate restriction produces a depletion of glycogen stores leading to excretion of bound water, and a ketogenic effect. The satiety effect of proteins and the boredom related to the diet are involved in the rapid weight loss due to spontaneously reducing food intake (Astrup et al. 2004). Moreover, it was suggested that the weight loss could be partially produced by the thermogenic effect of proteins (Mikkelsen et al. 2000). However, this fact apparently only involves a small fraction of the observed weight loss (Astrup et al. 2004). Moreover, high-protein diets with more than $30 \%$ energy as protein have been described as potentially harmful for the renal function, limiting the design of these strategies to induce weight loss (Martin et al. 2005); however, this issue remains to be elucidated, since no severe adverse effects have been reported so far.

Therefore, high-protein low-carbohydrate diets, which in some cases approach the high-fat low-carbohydrate models, look to be effective in the short term, but the long-term effects, not only on weight loss, but also on health and disease prevention are unknown; because of that, there is insufficient evidence to make recommendations for or against these types of diets.

\section{Conclusions}

In summary, different dietary approaches based upon changes in the macronutrient distribution rather than food restriction to treat obesity are becoming increasingly popular because they might favourably affect weight loss 


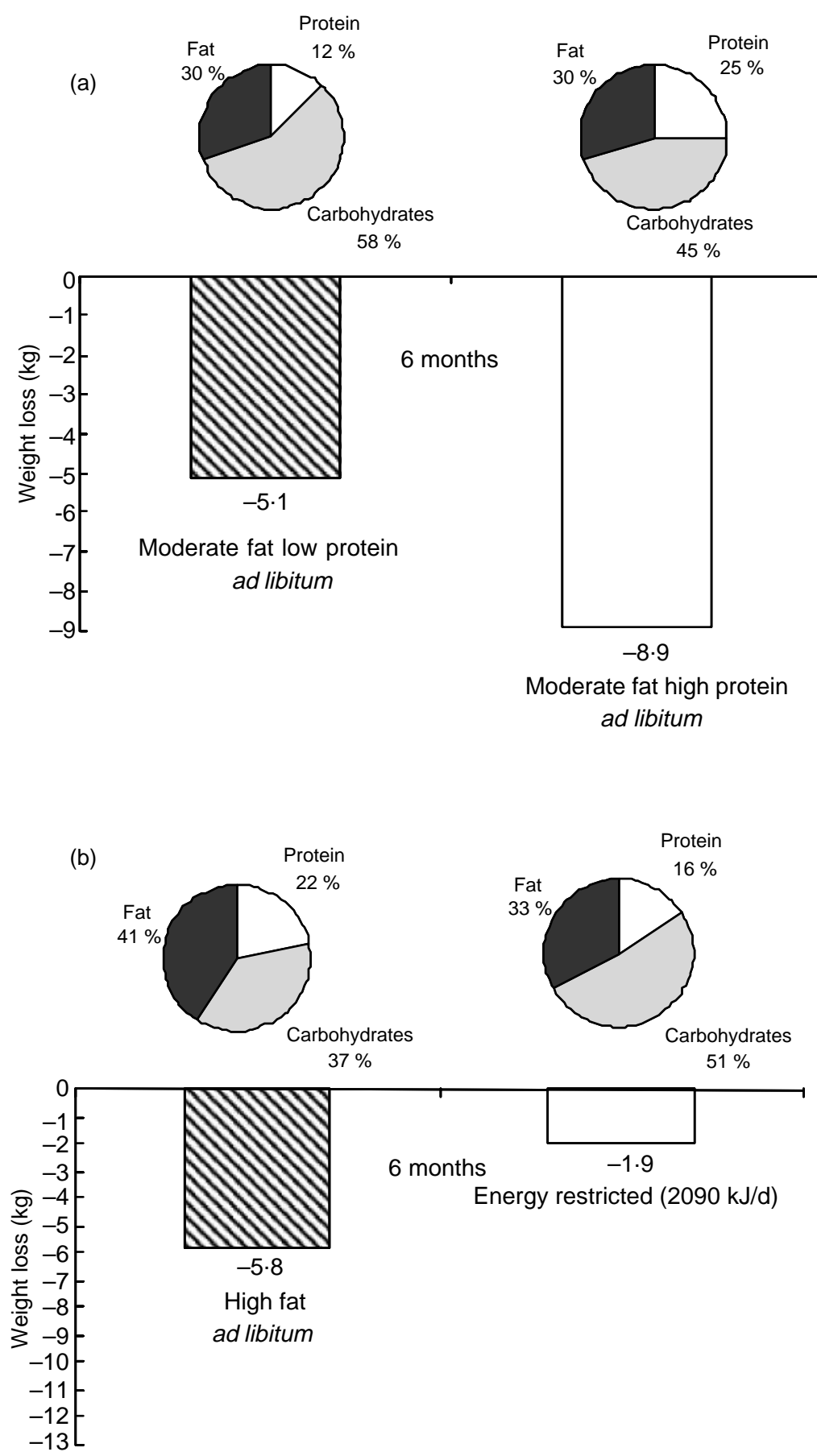

Fig. 5. Weight losses induced by high-protein diets (>20\% energy) as compared with other dietary interventions based on energy-restricted or ad libitum strategies. (a) From Skov et al. (1999); (b) from Samaha et al. (2003).

and the lipid profile. Therefore, regimens based on energy restriction and different macronutrient composition have been investigated with different success rates to be implemented in obese subjects in order to reduce and maintain weight losses. These diets, when energy is restricted, produce a moderate weight loss of about $0.5-1.0 \mathrm{~kg} /$ week, but when consumed ad libitum, and guided to low fat consumption or a high fat-low carbohydrate intake, produce an average weight loss of
$0.2-0.4 \mathrm{~kg} /$ week. However, there are several factors that determine weight loss induced by diets with different composition, such as the genetic predisposition, concomitant diseases and environmental influences. The current available evidence is insufficient to make recommendations for or against the use of low-carbohydrate high-fat or highcarbohydrate low-fat diets and further research is necessary, as well as an individualised design of the nutritional therapy to get adherence. 


\section{References}

Acheson KJ (2004) Carbohydrate and weight control: where do we stand? Current Opinion in Clinical Nutrition and Metabolic Care 7, 485-492.

Anderson JW, Konz EC \& Jenkins DJ (2000) Health advantages and disadvantages of weight-reducing diets: a computer analysis and critical review. Journal of the American College of Nutrition 19, 578-590.

Arai K, Miura J, Ohno M, Yokoyama J \& Ikeda Y (1992) Comparison of clinical usefulness of very-low-calorie diet and supplemental low-calorie diet. American Journal of Clinical Nutrition 56, 275S-276S.

Astrup A, Astrup A, Buemann B, Flint A \& Raben A (2002) Lowfat diets and energy balance: how does the evidence stand in 2002? Proceedings of the Nutrition Society 61, 299-309.

Astrup A, Meinert Larsen T \& Harper A (2004) Atkins and other low-carbohydrate diets: hoax or an effective tool for weight loss? Lancet 364, 897-899.

Astrup A, Toubro S, Raben A \& Skov AR (1997) The role of lowfat diets and fat substitutes in body weight management: what have we learned from clinical studies? Journal of the American Dietetic Association 97, S82-S87.

Atkins RC (1992) Dr. Atkins' New Diet Revolution. New York: Avon Books, Inc.

Bernstein RK (1997) Dr. Bernstein's Diabetes Solution. Boston, MA: Little, Brown \& Co.

Bravata DM, Sanders L, Huang J, Krumholz HM, Olkin I, Gardner CD \& Bravata DM (2003) Efficacy and safety of lowcarbohydrate diets: a systematic review. Journal of the American Medical Association 289, 1837-1850.

Brehm BJ, Seeley RJ, Daniels SR \& D'Alessio DA (2003) A randomized trial comparing a very low carbohydrate diet and a calorie-restricted low fat diet on body weight and cardiovascular risk factors in healthy women. Journal of Clinical Endocrinology and Metabolism 88, 1617-1623.

Cheah MH \& Kam PC (2005) Obesity: basic science and medical aspects relevant to anaesthetists. Anaesthesia 60, 1009-1021.

Colette C, Percheron C, Pares-Herbute N, Michel F, Pham TC, Brillant L, Descomps B \& Monnier L (2003) Exchanging carbohydrates for monounsaturated fats in energy-restricted diets: effects on metabolic profile and other cardiovascular risk factors. International Journal of Obesity and Related Metabolic Disorders 27, 648-656.

Dansinger ML, Gleason JA, Griffith JL, Selker HP \& Schaefer EJ (2005) Comparison of the Atkins, Ornish, Weight Watchers, and Zone diets for weight loss and heart disease risk reduction: a randomized trial. Journal of the American Medical Association 293, 43-53.

De Lorenzo A, Petroni ML, De Luca PP, Andreoli A, Morini P, Iacopino L, Innocente I \& Perriello G (2001) Use of quality control indices in moderately hypocaloric Mediterranean diet for treatment of obesity. Diabetes Nutrition and Metabolism 14, $181-188$.

Drewnowski A (1999) Intense sweeteners and energy density of foods: implications for weight control. European Journal of Clinical Nutrition 53, 757-763.

Due A, Toubro S, Skov AR \& Astrup A (2004) Effect of normal-fat diets, either medium or high in protein, on body weight in overweight subjects: a randomised 1-year trial. International Journal of Obesity and Related Metabolic Disorders 28, $1283-1290$.

Finer N (2001) Low-calorie diets and sustained weight loss. Obesity Research 9, 290S-294S.

Foster GD, Wadden TA, Peterson FJ, Letizia KA, Bartlett SJ \& Conill AM (1992) A controlled comparison of three very-low- calorie diets: effects on weight, body composition, and symptoms. American Journal of Clinical Nutrition 55, 811-817.

Foster GD, Wyatt HR, Hill JO, McGuckin BG, Brill C, Mohammed BS, Szapary PO, Rader DJ, Edman JS \& Klein S (2003) A randomized trial of a low-carbohydrate diet for obesity. New England Journal of Medicine 348, 2082-2090.

Freedman MR, King J \& Kennedy E (2001) Popular diets: a scientific review. Obesity Research 9, 1S-40S.

Gordon-Larsen P, Adair LS, Nelson MC \& Popkin BM (2004) Five-year obesity incidence in the transition period between adolescence and adulthood: the National Longitudinal Study of Adolescent Health. American Journal of Clinical Nutrition 80 , $569-575$

Grundy SM, Abate N \& Chandalia M (2002) Diet composition and the metabolic syndrome: what is the optimal fat intake? American Journal of Medicine 113, 25S-29S.

Hart KE \& Warriner EM (2005) Weight loss and biomedical health improvement on a very low calorie diet: the moderating role of history of weight cycling. Behavioral Medicine 30, 161-170.

Hays NP, Starling RD, Liu X, Sullivan DH, Trappe TA, Fluckey JD \& Evans WJ (2004) Effects of an ad libitum low-fat, highcarbohydrate diet on body weight, body composition, and fat distribution in older men and women: a randomized controlled trial. Archives of Internal Medicine 164, 210-217.

Heilbronn LK, Noakes M \& Clifton PM (1999) Effect of energy restriction, weight loss, and diet composition on plasma lipids and glucose in patients with type 2 diabetes. Diabetes Care 22, 889-895.

Hensrud DD (2004) Diet and obesity. Current Opinion in Gastroenterology 20, 119-124.

Jebb SA (2005) Dietary strategies for the prevention of obesity. Proceedings of the Nutrition Society 64, 217-227.

Johnston CS, Tjonn SL \& Swan PD (2004) High-protein, low-fat diets are effective for weight loss and favorably alter biomarkers in healthy adults. Journal of Nutrition 134, 586-591.

Kamrath RO, Plummer LJ, Sadur CN, Adler MA, Strader WJ, Young RL \& Weinstein RL (1992) Chotelelithiasis in patients treated with a very-low-calorie diet. American Journal of Clinical Nutrition 56, 255S-257S.

Kasai M, Nosaka N, Maki H, Negishi S, Aoyama T, Nakamura M, Suzuki Y, Tsuji H, Uto H, Okazaki M \& Kondo K (2003) Effect of dietary medium- and long-chain triacylglycerols (MLCT) on accumulation of body fat in healthy humans. Asia Pacific Journal of Clinical Nutrition 12, 151-160.

Kekwick A \& Pawan GL (1956) Calorie intake in relation to bodyweight changes in the obese. Lancet 271, 155-161.

Kemper HC, Stasse-Wolthuis M \& Bosman W (2004) The prevention and treatment of overweight and obesity. Summary of the advisory report by the Health Council of The Netherlands. Netherlands Journal of Medicine 62, 10-17.

Labayen I, Diez N, Parra MD, Gonzalez A \& Martinez JA (2004) Time-course changes in macronutrient metabolism induced by a nutritionally balanced low-calorie diet in obese women. International Journal of Food Sciences and Nutrition 55, 27-35.

Lantz H, Peltonen M, Agren L \& Torgerson JS (2003) Intermittent versus on-demand use of a very low calorie diet: a randomized 2year clinical trial. Journal of Internal Medicine 253, 463-471.

Layman DK, Boileau RA, Erickson DJ, Painter JE, Shiue H, Sather C \& Christou DD (2003) A reduced ratio of dietary carbohydrate to protein improves body composition and blood lipid profiles during weight loss in adult women. Journal of Nutrition 133, 411-417.

Luscombe ND, Clifton PM, Noakes M, Farnsworth E \& Wittert G (2003) Effect of a high-protein, energy-restricted diet on weight loss and energy expenditure after weight stabilization in hyperinsulinemic subjects. International Journal of Obesity and Related Metabolic Disorders 27, 582-590. 
McAuley KA, Hopkins CM, Smith KJ, McLay RT, Williams SM, Taylor RW \& Mann JI (2005) Comparison of high-fat and highprotein diets with a high-carbohydrate diet in insulin-resistant obese women. Diabetologia 48, 8-16.

McManus K, Antinoro L \& Sacks F (2001) A randomized controlled trial of a moderate-fat, low-energy diet compared with a low fat, low-energy diet for weight loss in overweight adults. International Journal of Obesity and Related Metabolic Disorders 25, 1503-1511.

Marti A, Moreno-Aliaga MJ, Hebebrand J \& Martinez JA (2004) Genes, lifestyles and obesity. International Journal of Obesity and Related Metabolic Disorders 28, Suppl. 3, S29-S36.

Martin WF, Armstrong LE \& Rodriguez NR (2005) Dietary protein intake and renal function. Nutrition and Metabolism 2, 25.

Mathus-Vliegen EM; Balance Study Group (2005) Long-term maintenance of weight loss with sibutramine in a GP setting following a specialist guided very-low-calorie diet: a doubleblind, placebo-controlled, parallel group study. European Journal of Clinical Nutrition 59, S31-S38.

Meksawan K, Pendergast DR, Leddy JJ, Mason M, Horvath PJ \& Awad AB (2004) Effect of low and high fat diets on nutrient intakes and selected cardiovascular risk factors in sedentary men and women. Journal of the American College of Nutrition 23, $131-140$.

Mikkelsen PB, Toubro S \& Astrup A (2000) Effect of fat-reduced diets on 24-h energy expenditure: comparisons between animal protein, vegetable protein, and carbohydrate. American Journal of Clinical Nutrition 72, 1135-1141.

Mithieux G, Misery P, Magnan C, Pillot B, Gautier-Stein A, Bernard C, Rajas F \& Zitoun C (2005) Portal sensing of intestinal gluconeogenesis is a mechanistic link in the diminution of food intake induced by diet protein. Cell Metabolism 2, 321-329.

Monnier L, Colette C, Percheron C \& Boniface H (2000) Verylow-calorie-diets: is there a place for them in the management of the obese diabetics. Diabetes Metabolism 26, 46-51.

Mozaffarian D (2005) Effects of dietary fats versus carbohydrates on coronary heart disease: a review of the evidence. Current Atherosclerosis Reports 7, 435-445.

Mueller-Cunningham WM, Quintana R \& Kasim-Karakas SE (2003) An ad libitum, very low-fat diet results in weight loss and changes in nutrient intake in postmenopausal women. Journal of the American Dietetic Association 103, 1600-1606.

Mustajoki P \& Pekkarinen T (2001) Very low energy diets in the treatment of obesity. Obesity Research 2, 61-72.

Nettleton JA \& Katz R (2005) n-3 Long-chain polyunsaturated fatty acids in type 2 diabetes: a review. Journal of the American Dietetic Association 105, 428-440.

Noakes M, Keogh JB, Foster PR \& Clifton PM (2005) Effect of an energy-restricted, high-protein, low-fat diet relative to a conventional high-carbohydrate, low-fat diet on weight loss, body composition, nutritional status, and markers of cardiovascular health in obese women. American Journal of Clinical Nutrition 81, 1298-1306.

O’Neil PM \& Jarrell MP (1992) Psychological aspects of obesity and very-low-calorie diets. American Journal of Clinical Nutrition 56, 185S-189S.

Ornish D (2004) Was Dr Atkins right? Journal of the American Dietetic Association 104, 537-542.

Parker B, Noakes M, Luscombe N \& Clifton P (2002) Effect of a high-protein, high-monounsaturated fat weight loss diet on glycemic control and lipid levels in type 2 diabetes. Diabetes Care 25, 425-430.

Pelkman CL, Fishell VK, Maddox DH, Pearson TA, Mauger DT \& Kris-Etherton PM (2004) Effects of moderate-fat (from monounsaturated fat) and low-fat weight-loss diets on the serum lipid profile in overweight and obese men and women. American Journal of Clinical Nutrition 79, 204-212.

Petersen M \& Harper A (2004) Weight loss strategies a change of focus is required. Obesity Review 5, 239-240.

Petersen M, Taylor MA, Saris WH, Verdich C, Toubro S, Macdonald I, Rössner S, Stich V, Guy-Grand B, Langin D, et al.; The NUGENOB Consortium (2006) Randomised, multi-centre trial of two hypoenergetic diets with different fat content in obese subjects. International Journal of Obesity (London) 30, $552-560$.

Pirozzo S, Summerbell C, Cameron C \& Glasziou P (2002) Advice on low-fat diets for obesity. Cochrane Database Systematic Review, CD003640.

Plodkowski RA \& St Jeor ST (2003) Medical nutrition therapy for the treatment of obesity. Endocrinology and Metabolism Clinics of North America 32, 935-965.

Popkin BM (2001) The nutrition transition and obesity in the developing world. Journal of Nutrition 131, 871S-873S.

Popkin BM \& Gordon-Larsen P (2004) The nutrition transition: worldwide obesity dynamics and their determinants. International Journal of Obesity and Related Metabolic Disorders 28, S2-S9.

Poppitt SD, Keogh GF, Prentice AM, Williams DE, Sonnemans HM, Valk EE, Robinson E \& Wareham NJ (2002) Long-term effects of ad libitum low-fat, high-carbohydrate diets on body weight and serum lipids in overweight subjects with metabolic syndrome. American Journal of Clinical Nutrition 75, 11-20.

Raben A, Astrup A, Vasilaras TH, Prentice AM, Zunft HJ, Formiguera X, Verboeket-van de Venne WP, Poppitt SD, Seppelt B, Johnston S, et al. (2002) The CARMEN trial: increased intake of carbohydrates - simple or complex - and unchanged blood lipids in overweight subjects (article in Danish). Ugeskrift for Laeger 164, 627-631.

Raynor HA, Jeffery RW, Tate DF \& Wing RR (2004) Relationship between changes in food group variety, dietary intake, and weight during obesity treatment. International Journal of Obesity 23, 813-820.

Roberts DCK (2001) Quick weight loss: sorting fad from fact. Medicine Journal of Australia 175, 637-640.

Roberts SB (2003) Glycemic index and satiety. Nutrition in Clinical Care 6, 20-26.

Rodriguez C, Martínez de Morentin B, Parra $\mathrm{M}^{\mathrm{a}} \mathrm{D}$, Perez S \& Martinez JA (2005) Nutrientes y otros componentes de los alimentos implicados en la regulación del peso corporal (Nutrients and other food components implicated in the regulation of body weight). Revista Española de Obesidad 8, $5-11$.

Ryttig KR, Flaten H \& Rossner S (1997) Long-term effects of a very low calorie diet (Nutrilett) in obesity treatment. A prospective, randomized, comparison between VLCD and a hypocaloric diet + behavior modification and their combination. International Journal of Obesity and Related Metabolic Disorders 21, 574-579.

Samaha FF, Iqbal N, Seshadri P, Chicano KL, Daily DA, McGrory J, Williams T, Williams M, Gracely EJ \& Stern L (2003) A low-carbohydrate as compared with a low-fat diet in severe obesity. New England Journal of Medicine 348, 2074-2081.

Saris WH, Astrup A, Prentice AM, Zunft HJ, Formiguera X, Verboeket-van de Venne WP, Raben A, Poppitt SD, Seppelt B, Johnston S, et al. (2000) Randomized controlled trial of changes in dietary carbohydrate/fat ratio and simple vs complex carbohydrates on body weight and blood lipids: the CARMEN study. The Carbohydrate Ratio Management in European National diets. International Journal of Obesity and Related Metabolic Disorders 24, 1310-1318. 
Schrager S (2005) Dietary calcium intake and obesity. Journal of American Board of Family Practice 18, 205-210.

Skov AR, Toubro S, Ronn B, Holm L \& Astrup A (1999) Randomized trial on protein vs carbohydrate in ad libitum fat reduced diet for the treatment of obesity. International Journal of Obesity and Related Metabolic Disorders 23, 528-536.

Slavin JL (2005) Dietary fiber and body weight. Nutrition 21, 411-418.

Stern L, Iqbal N, Seshadri P, Chicano KL, Daily DA, McGrory J, Williams M, Gracely EJ \& Samaha FF (2004) The effects of low-carbohydrate versus conventional weight loss diets in severely obese adults: one-year follow-up of a randomised trial. Annals of Internal Medicine 140, 778-785.

St-Onge MP \& Jones PJ (2003) Greater rise in fat oxidation with medium-chain triglyceride consumption relative to long-chain triglyceride is associated with lower initial body weight and greater loss of subcutaneous adipose tissue. International Journal of Obesity and Related Metabolic Disorders 27, $1565-1571$.

Strasser B \& Pichler B (2004) Diet and physical activity in the treatment of obesity. Wiener Medizinische Wochenschrift 154, $313-319$.

Stubbs RJ, van Wyk MC, Johnstone AM \& Harbron CG (1996) Breakfasts high in protein, fat or carbohydrate: effect on withinday appetite and energy balance. European Journal of Clinical Nutrition 50, 409-417.

Swinburn BA, Caterson I, Seidell JC \& James WP (2004) Diet, nutrition and the prevention of excess weight gain and obesity. Public Health Nutrition 7, 123-146.

Toubro S \& Astrup A (1997) Randomised comparison of diets for maintaining obese subjects' weight after major weight loss: ad lib, low fat, high carbohydrate diet $v$ s fixed energy intake. British Medical Journal 314, 29-34.

Volek JS, Gomez AL \& Kraemer WJ (2000) Fasting lipoprotein and postprandial triacylglycerol responses to a low-carbohydrate diet supplemented with n-3 fatty acids. Journal of the American College of Nutrition 19, 383-391.

Volek JS, Sharman MJ, Gomez AL, DiPasquale C, Roti M, Pumerantz A \& Kraemer WJ (2004) Comparison of a very low-carbohydrate and low-fat diet on fasting lipids, LDL subclasses, insulin resistance, and postprandial lipemic responses in overweight women. Journal of the American College of Nutrition 23, 177-184.
Volek JS, Vanheest JL \& Forsythe CE (2005) Diet and exercise for weight loss: a review of current issues. Sports Medicine 35, 1-9.

Wadden TA, Foster GD, Letizia KA \& Mullen JL (1990) Longterm effects of dieting on resting metabolic rate in obese outpatients. Journal of the American Medical Association 264, $707-711$.

Wadden TA \& Stunkard AJ (1986) Controlled trial of very low calorie diet, behavior therapy, and their combination in the treatment of obesity. Journal of Consulting and Clinical Psychology 54, 482-488.

Wadden TA, Stunkard AJ \& Brownell KD (1983) Very low calorie diets: their efficacy, safety, and future. Annals of Internal Medicine 99, 675-684.

Wadden TA, Stunkard AJ, Brownell KD \& Day SC (1985) A comparison of two very-low-calorie diets: protein-sparingmodified fast versus protein-formula-liquid diet. American Journal of Clinical Nutrition 41, 533-539.

Walker KZ \& O'Dea K (2001) Is a low fat diet the optimal way to cut energy intake over the long-term in overweight people? Nutrition Metabolism and Cardiovascular Diseases 11, 244-248.

Weigle DS, Breen PA, Matthys CC, Callahan HS, Meeuws KE, Burden VR \& Purnell JQ (2005) A high-protein diet induces sustained reductions in appetite, ad libitum caloric intake, and body weight despite compensatory changes in diurnal plasma leptin and ghrelin concentrations. American Journal of Clinical Nutrition 82, 41-48.

Wilkinson DL \& McCargar L (2004) Is there an optimal macronutrient mix for weight loss and weight maintenance? Best Practice and Research. Clinical Gastroenterology 18, $1031-1047$.

Wing RR (1995) Use of very-low-calorie diets in the treatment of obese persons with non-insulin-dependent diabetes mellitus. Journal of the American Dietetic Association 95, 569-572.

Wyatt HR (2003) The prevalence of obesity. Primary Care 30, 267-279.

Yancy WS, Olsen MK, Guyton JR, Bakst RP \& Westman EC (2004) A low carbohydrate, ketogenic diet versus a low fat diet to treat obesity and hyperlipidemia. Annals of Internal Medicine 140, 769-777.

Yang MU \& van Itallie T (1976) Composition of weight lost during short-term weight reduction. Metabolic responses of obese subjects to starvation and low-calorie ketogenic and nonketogenic diets. Journal of Clinical Investigation 58, 722-730. 